\title{
Activation of JNK and high expression level of CDI33 predict a poor response to sorafenib in hepatocellular carcinoma
}

\author{
S Hagiwara', M Kudo', T Nagai', T Inoue', K Ueshima', N Nishida', T Watanabe ${ }^{2}$ and T Sakurai*,' \\ 'Department of Gastroenterology and Hepatology, Kinki University, 377-2, Osaka-Sayama, Osaka 589-85II, Japan; ${ }^{2}$ Center for Innovation in \\ Immunoregulative Technology and Therapeutics, Kyoto University Graduate School of Medicine, Kyoto, Japan
}

\begin{abstract}
BACKGROUND: Hepatocellular carcinoma (HCC) ranks as the third leading cause of cancer deaths worldwide. While sorafenib, a multikinase inhibitor targeting the Raf/extracellular signal-regulated protein kinase (ERK) pathway, has been shown recently to provide a survival advantage to patients with advanced HCC, a predictive biomarker has not been developed. We studied whether c-Jun $\mathrm{N}$-terminal kinase (JNK), which promotes liver carcinogenesis in mice, affects therapeutic response to sorafenib in HCC patients.

METHODS: We collected pathological specimens from 39 patients with advanced HCC before starting sorafenib treatment, and measured JNK activity in HCCs.

RESULTS: In patients treated with sorafenib, the expression of phospho-c-Jun in HCC, as a read out of JNK activity, was significantly higher $(P<0.00 \mathrm{I})$ in the non-responder group than in the responder group. $\mathrm{c}$-Jun $\mathrm{N}$-terminal kinase activation in HCC was associated with a decreased time to progression and a poor overall survival $(P=0.0028$ and $P=0.0008$, respectively).

CONCLUSION: In addition, JNK activity was significantly correlated with CDI33 expression level. Correspondingly, high expression level of CDI33 was linked to a poor response to sorafenib. Furthermore, D-JNKi, a specific JNK inhibitor, reduced the growth of xenografted $\mathrm{CDI} 33^{+}$cells in athymic mice. In conclusion, JNK activation was positively correlated with CDI33 expression level and inversely correlated with the therapeutic response to sorafenib, suggesting that JNK activity may be considered as a new predictive biomarker for response to sorafenib treatment.

British Journal of Cancer (2012) 106, 1997-2003. doi:I0.1038/bjc.2012.145 www.bjcancer.com

Published online 17 May 2012

(C) 2012 Cancer Research UK
\end{abstract}

Keywords: c-Jun; extracellular signal-regulated protein kinase (ERK); cancer stem cells; CDI33

Unlike most solid tumours, the incidence and mortality of hepatocellular carcinoma (HCC) have increased in the United States and Europe in the past decade. Most patients are diagnosed at advanced stages, so there is an urgent need for new systemic therapies. Studies in patients with lung, breast or colorectal cancers have indicated that the heterogeneity of cancer cells within a tumour affect its response to therapeutics designed to targetspecific molecules. When tumour progression requires alterations in specific signalling pathways, drugs that selectively block them might slow tumour growth. Identification of molecules that mediate tumour progression, and trials that monitor them as biomarkers, might lead to personalised therapy; reagents that interfere with signalling pathways required for HCC progression might be used to treat selected populations, and thereby maximise the efficacy and cost benefit. However, no specific alterations are yet known to be implicated in HCC progression, so it is important to improve our understanding of its molecular pathogenesis.

Mitogen-activated protein kinases (MAPKs), serine/threoninespecific protein kinases, respond to extracellular stimuli and have a pivotal role in various cellular processes, such as gene expression, mitosis, differentiation, proliferation and cell survival/apoptosis (Chang and Karin, 2001; Dhillon et al, 2007). Mitogen-activated protein kinase comprises the extracellular

*Correspondence: Dr T Sakurai; E-mail: sakurai@med.kindai.ac.jp. Received 4 January 2012; revised 20 March 2012; accepted 22 March 2012; published online 17 May 2012 signal-regulated protein kinase (ERK), c-Jun N-terminal kinase (JNK) and p38MAPK. Accumulating evidence suggests that activation or inactivation of MAPK regulates inflammatory responses and provides a growth advantage to hepatocytes during malignant transformation and liver tumourigenesis (Sakurai et al, 2006, 2008; Hui et al, 2007; Whittaker et al, 2010). Abnormal activation of ERK is often observed in human HCC. It has been shown that systemic administration of sorafenib, a tyrosine kinase inhibitor targeting the Raf/ERK pathway, extended the survival of patients with advanced-stage HCC significantly in several clinical trials (Abou-Alfa et al, 2006; Llovet et al, 2008). Mouse cancer models have shown that the JNK pathway is implicated in regulating liver carcinogenesis. c-Jun $\mathrm{N}$-terminal kinase activation contributes to hepatocyte proliferation and HCC development by regulating cyclin D and vascular endothelial growth factor (VEGF), a potent proangiogenic substance responsible for tumour neovascularisation (Schwabe et al, 2003; Sakurai et al, 2006; Sakurai and Kudo, 2011). c-Jun, a downstream target of JNK, promotes chemically induced liver cancer development through suppression of the p53 pathway (Eferl et al, 2003). Proliferation of HCC cells requires JNK-dependent downregulation of p21 (Hui et al, 2008). However, the extent of the involvement of JNK in the development of human liver cancers is unknown. Recently, we have reported that activation of JNK in non-cancerous liver tissue predicts a high risk of recurrence after hepatic resection for hepatocellular carcinoma, suggesting the importance of JNK in human HCC (Hagiwara et al, 2011). 
A novel theory in the field of tumour biology postulates that the capacity to maintain tumour formation and growth is found in a small population of cells, called tumour-initiating cells or cancer stem cells. The stem cell-like characteristics of these cells are believed to render these cells resistant to conventional therapies and allow them to drive tumourigenesis. CD133, a transmembrance glycoprotein, is a valuable marker of cancer stem cell and is expressed in $1-5 \%$ of human HCC, while absent in normal liver cells (Ma et al, 2007). In addition to its role as a marker, CD133 has been reported to play a functional part in regulating tumourigenesis of liver cancer stem cells via regulating IL-8, CXCL1 and ERK signalling (Tang et al, 2011).

\section{PATIENTS AND METHODS}

\section{Patients}

From May 2009 to June 2010, 39 patients with refractory HCC, which could not be controlled by standard therapeutic modalities, received sorafenib (Nexavar; Bayer HealthCare PharmaceuticalsOnyx Pharmaceuticals, Leverkusen, Germany) at Kinki University Hospital. All pathological specimens of HCC were taken by needle biopsy before sorafenib treatment.

The study protocols conformed to the ethical guidelines of the 1975 Declaration of Helsinki and were approved by the institutional review boards. Written informed consent was obtained from all patients for subsequent use of their collected tissues.

\section{Eligibility criteria, treatment regimen and assessment of response to sorafenib}

The eligibility criteria for sorafenib therapy were (1) advanced HCC, which was uncontrollable with standard treatments, or HCC with distant metastasis; (2) age $<81$ years; (3) an Eastern Cooperative Group performance status of 0 or 1 ; (4) Child-Pugh grade A; (5) encephalopathy degree 0 ; (6) leukocyte count $>3000$ cells $\mathrm{mm}^{-3}$, haemoglobin level $>10 \mathrm{~g} \mathrm{dl}^{-1}$, platelet count $>80000$ cells mm ${ }^{-3}$; and (7) serum creatinine $<1.5 \mathrm{mg} \mathrm{dl}^{-1}$, serum aspartate aminotransferase $<200 \mathrm{IUl}^{-1}$, serum alanine aminotransferase $<200 \mathrm{IUl}^{-1}$ and serum total bilirubin $<3.0 \mathrm{mg} \mathrm{dl}^{-1}$. These criteria were based on the susceptibility to adverse side effects. The diagnosis of HCC was made based on haematoxylin-eosin staining of histopathological specimens in all patients.

Sorafenib was given orally at a daily dose of $800 \mathrm{mg}$, divided into two equal doses. Treatment interruptions and up to two dose reductions (first to $400 \mathrm{mg}$ once daily and then to $400 \mathrm{mg}$ every 2 days) were permitted for drug-related adverse effects (National Cancer Institute-Common Terminology Criteria (NCI-CTC, version 3)). Treatment was continued until the occurrence of radiologic progression, as defined by the Response Evaluation Criteria in Solid Tumors (RECIST, Version 1.1).

Assessed by contrast enhanced computed tomography or magnetic resonance imaging every 4 weeks, therapeutic response to sorafenib was defined according to the criteria of RECIST (Version 1.1). A partial response (PR) was defined as at least $30 \%$ decrease in the sum of the longest diameter of target lesions with the baseline sum of the longest diameter of target lesions as the reference. Progressive disease (PD) was defined as at least $20 \%$ increase in the sum of the longest diameter of target lesions. Stable disease (SD) was defined as meeting neither PR nor PD criteria. When the response achieved for intrahepatic HCC differed from that for extrahepatic HCC, the worse response was determined as the achieved response. Assessment of response was introduced best overall response of RECIST.

\section{Immunohistochemistry}

Immunohistochemical analysis was performed on paraffin sections of human HCC and mouse tumours. Immunohistochemical staining was carried out with antibodies raised against phosphoc-Jun (Ser63; $1: 100)$, phospho-JNK $(1: 100)$ and CD133 (1:100) from Cell Signaling Technology (Danvers, MA, USA) and visualised using Dako LSAB System-HRP (Dako, Carpinteria, CA, USA). Five fields of images per sample were taken and total and stain-positive nuclei were counted by Image $\mathrm{J}$ software (NIH, Bethesda, MD, USA).

\section{Western blot analysis}

To prepare tissue lysate, HCC tissue was homogenised with CelLytic-MT Mammalian Tissue Lysis/Extraction reagent (Sigma-Aldrich, St Louis, MO, USA) with protease inhibitor, Complete (Roche Diagnostics, Mannheim, Germany), and phosphatase inhibitor (Toyobo, Osaka, Japan) and centrifuged. Equal protein amounts of tissue lysates were electrophoresed through a reducing SDS polyacrylamide gel and electroblotted onto a PVDF membrane. The membrane was blocked and incubated with primary antibodies for CD133, phospho-c-Jun, c-Jun, phosphoERK1/2, ERK1/2 from Cell Signaling Technology (Beverly, MA, USA) and $\beta$-actin (Sigma-Aldrich). The levels of each protein were detected with horseradish peroxide-linked secondary antibodies and the ECL plus System (GE Healthcare, Piscataway, NJ, USA). To evaluate the signal intensity, obtained western blot image data were quantified using Image J software (NIH).

\section{Inoculation of sorted $\mathrm{CD}_{133}{ }^{+} \mathrm{HCC}$ cells into nude mice}

Human liver cancer cell line HepG2 and HuH7 obtained from the Riken Cell Bank (Tsukuba, Japan) were cultured in DMEM with $100 \mathrm{U} \mathrm{ml}^{-1}$ penicillin, $100 \mu \mathrm{g} \mathrm{ml}^{-1}$ streptomycin and $10 \%$ (FBS) at $37^{\circ} \mathrm{C}$ under $5 \% \mathrm{CO}_{2} / 95 \%$ air. For isolating $\mathrm{CD} 133$-positive and negative cells, cells were collected by trypsin treatment, washed twice with $1 \%$ BSA/PBS and labelled with anti-CD133-allophycocyanin antibody (Miltenyi Biotec, Bergisch Gladbach, Germany) for $20 \mathrm{~min}$ on ice, in the dark. Then, cells were washed once in icecold $1 \%$ BSA/PBS, and sorted on a FACS Vantage SE (BD, San Diego, CA, USA). CD133-positive and -negative cells were collected separately, washed with PBS and cultured under normal condition for 5 days. Cells were collected by trypsin treatment and suspended in mixture of DMEM and Matrigel (BD) $(1: 1)$, and injected. $\mathrm{CD}_{133^{+}}$cells were subcutaneously inoculated into 6-week-old female $\mathrm{BALB} / \mathrm{c}$ nude mice. From 1 week after subcutaneous inoculation, TAT control peptide and D-JNKi were administered at $25 \mathrm{nmol}$ per mouse once a week and the mice were autopsied 4 weeks later. D-JNKi is an efficient inhibitor of the action of all three JNK isoforms and is made by linking the 20 amino-acid terminal JNK-inhibitory sequence (i.e., the JNK-binding domain of JIP-1/IB1) to a 10-amino acid HIV-TAT transporter sequence.

All animal procedures were performed according to approved protocols and in accordance with the recommendations for the proper care and use of laboratory animals. The Medical Ethics Committee of Kinki University School of Medicine approved the present study.

\section{Statistical analysis}

Relationships between the parameters of the patients treated with sorafenib were investigated using Student's $t$-test, the MannWhitney $U$-test and Fisher's exact test. Cumulative survival and time-to-progression (TTP) curves were constructed using the Kaplan-Meier method and compared using the log-rank test. The relationship between numeric data (e.g., number on PCNApositive tumour cells) was determined using Student's $t$-test. 
All analyses were performed using the SPSS software (version 11.5; SPSS Inc., Chicago, IL, USA).

\section{RESULTS}

\section{Association between JNK activation and poor therapeutic response to sorafenib}

Among 39 patients treated, a complete response and $\mathrm{PR}$ was achieved in $0(0 \%)$ and $5(12.8 \%)$, respectively. The overall response rate was $12.8 \%$. Stable disease was noted in 13 patients (33\%), and the disease control rate (complete response $+\mathrm{PR}+\mathrm{SD}$ ) was $46.2 \%$. Progressive disease was noted in 17 patients $(43.6 \%)$. Four patients were excluded from the assessment of response because they died of rupture of HCC or of oesophageal varices after the start of treatment and computed tomography could not be performed. No significant difference was observed in any of nine parameters such as age, sex, the cause of disease, tumour grade or previous therapy, between the responder group and the non-responder group (Table 1). We evaluated the change in tumour blood flow by using CT scan to confirm how sorafenib worked. In 13 out of 18 responders (72\%), arterial blood supply was decreased while in 8 out of 17 non-responders $(47 \%)$ the arterial blood flow was decreased.

We investigated the association between the therapeutic response to sorafenib and JNK activation using HCC specimens collected before treatment. As shown in Figure 1, phospho-JNK/c-Jun expression in HCC cells was significantly higher in the nonresponder group than in the responder group.

Table I Comparison of patient characteristics according to the anticancer effect

\begin{tabular}{|c|c|c|c|}
\hline Variable & $\begin{array}{l}\text { Responder } \\
(P R+S D) \\
(n=18)\end{array}$ & $\begin{array}{l}\text { Non-responder } \\
(\text { PD) } \\
(n=17)\end{array}$ & $P$-value \\
\hline Age - years & $70.5(54-78)$ & $74(35-80)$ & 0.95 \\
\hline $\begin{array}{l}\text { Sex }- \text { no. }(\%) \\
\text { Male } \\
\text { Female }\end{array}$ & $\begin{array}{r}13(72) \\
5(28)\end{array}$ & $\begin{array}{r}12(7 \mid) \\
5(29)\end{array}$ & 1 \\
\hline $\begin{array}{l}\text { Cause of disease - no. (\%) } \\
\text { Hepatitis B } \\
\text { Hepatitis C } \\
\text { Non-B, non-C }\end{array}$ & $\begin{array}{l}3(17) \\
9(50) \\
6(33)\end{array}$ & $\begin{array}{l}4(24) \\
9(53) \\
4(24)\end{array}$ & 0.82 \\
\hline $\begin{array}{c}\text { ECOG performance status - no. (\%) } \\
0 \\
1\end{array}$ & $\begin{aligned} 18 & (100) \\
0 & (0)\end{aligned}$ & $\begin{array}{c}16(94) \\
1(6)\end{array}$ & 0.49 \\
\hline $\begin{array}{l}\text { BCLC stage - no. (\%) } \\
\text { B (intermediate) } \\
\text { C (advanced) }\end{array}$ & $\begin{array}{r}11(61) \\
7(39)\end{array}$ & $\begin{array}{l}8(47) \\
9(53)\end{array}$ & 0.51 \\
\hline $\begin{array}{l}\text { Tumour grade - no. (\%) } \\
\text { Well } \\
\text { Moderate } \\
\text { Poor }\end{array}$ & $\begin{array}{r}2(11) \\
11(61) \\
5(28)\end{array}$ & $\begin{aligned} & 0(0) \\
& 12(71) \\
& 5(29)\end{aligned}$ & 0.62 \\
\hline $\operatorname{AFP}\left(\mathrm{ng} \mathrm{ml}^{-1}\right)-$ median (range) & $276(2-22619)$ & $89(3-228540)$ & 0.56 \\
\hline $\mathrm{DCP}\left(\mathrm{mAU} \mathrm{ml}^{-1}\right)$ - median (range) & $64 \mid(5-26624)$ & $481.5(9-61180)$ & 0.93 \\
\hline $\begin{array}{l}\text { Previous therapy (last) - no. (\%) } \\
\text { OP } \\
\text { RFA } \\
\text { TACE } \\
\text { HAIC } \\
\text { None }\end{array}$ & $\begin{aligned} & 1(6) \\
& 1(6) \\
& 11(61) \\
& 3(17) \\
& 2(11)\end{aligned}$ & $\begin{array}{l}5(29) \\
2(12) \\
10(59) \\
0(0) \\
0(0)\end{array}$ & 0.09 \\
\hline
\end{tabular}

Abbreviations: $\mathrm{ECOG}=$ Eastern Cooperative Oncology Group; $\mathrm{BCLC}=$ Barcelona Clinic Liver Cancer; $\quad$ AFP $=\alpha$-fetoprotein; $\quad D C P=$ des- $\gamma$-carboxyprothrombin; $\mathrm{OP}=$ operation; $\mathrm{RFA}=$ radiofrequency ablation; $\mathrm{TACE}=$ transcatheter arterial chemoembolization; HAIC = hepatic arterial chemotherapy using implanted port system; $\mathrm{PR}=$ partial response; $\mathrm{SD}=$ stable disease; $\mathrm{PD}=$ progressive disease.

\section{Association between JNK activation and poor prognosis in patients treated with sorafenib}

The median TTP was 2.0 months (95\% confidence interval: 0-7.9 months). The cumulative progression-free survival rates at 3,6 and 12 months were $49 \%, 44 \%$ and $29 \%$, respectively. All enrolled patients were also included in a survival assessment. Twenty-five patients were still alive at the end of the observation period (median: 6.0 months, range: $1.3-12.1$ months), while 14 patients had died. The causes of death were tumour progression $(n=10)$ and rupture of HCC or oesophageal varices $(n=4)$. The median survival time was 12.1 months (95\% confidence interval: 7.9-16.4 months). The cumulative survival rate at 3, 6 and 12 months were $81 \%, 75 \%$ and $56 \%$, respectively.

We examined the impact of JNK activation in HCC cells on the prognosis of patients treated with sorafenib. Hepatocellular carcinoma specimens collected by needle biopsy before sorafenib treatment were stained with anti-phospho-c-Jun antibody and the data were quantified. Patients were divided into high and low p-c-Jun expression groups by setting the median level as the cutoff between the two groups. As shown in Figure 2A, a log-rank test using the Kaplan-Meier method showed significant TTP prolongation in the low $\mathrm{p}$-c-Jun expression group, compared with the high expression group $(P=0.0028)$. We also found significant prolongation of overall survival (OS) in the low p-c-Jun expression group compared with the high expression group $(P=0.0008$; Figure $2 \mathrm{~B})$. The duration of sorafenib treatment was $151 \pm 116$ days in the low p-c-Jun group and $80 \pm 97$ days in the high p-c-Jun group.

A
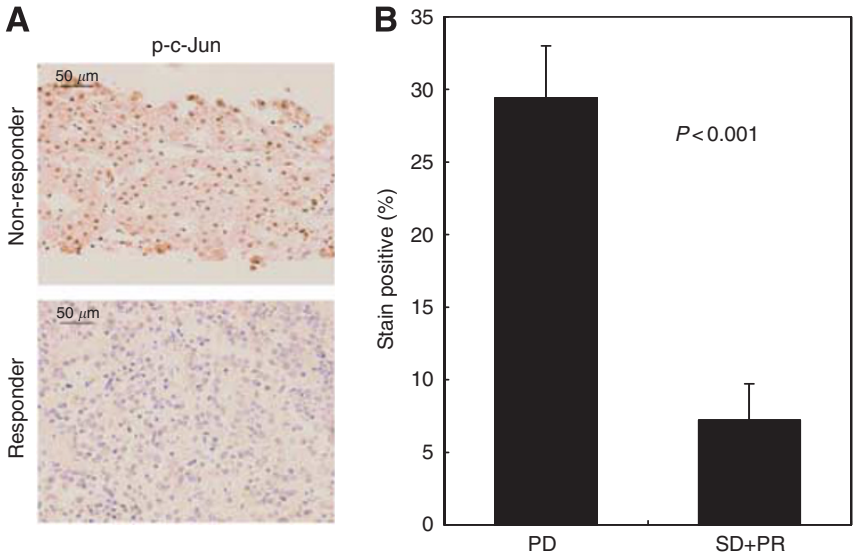

C

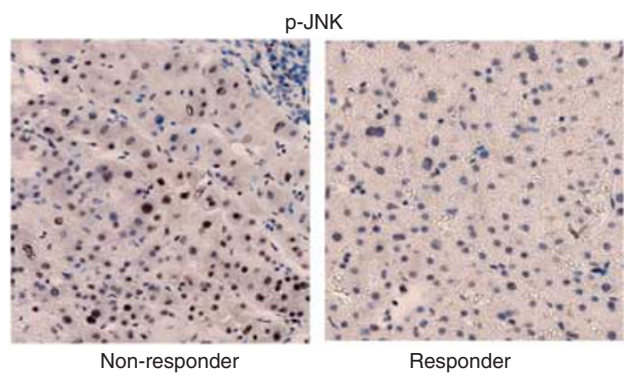

Figure I Association between JNK activation and poor therapeutic response to sorafenib in HCC. (A) Expression of phospho-c-Jun in HCC of patients with poor response (PD, $n=18$ ) and favourable response to sorafenib (PR, SD, $n=17$ ). Paraffin-embedded liver sections were immunostained with anti-phospho-c-Jun antibody. (B) Frequency of phospho-c-Jun-positive cells in HCCs. Data are the mean values \pm s.e. (C) Expression of phospho-JNK in HCC of patients with poor response (PD) and favourable response to sorafenib (PR, SD). Paraffin-embedded liver sections were immunostained with anti-phospho-JNK antibody. 

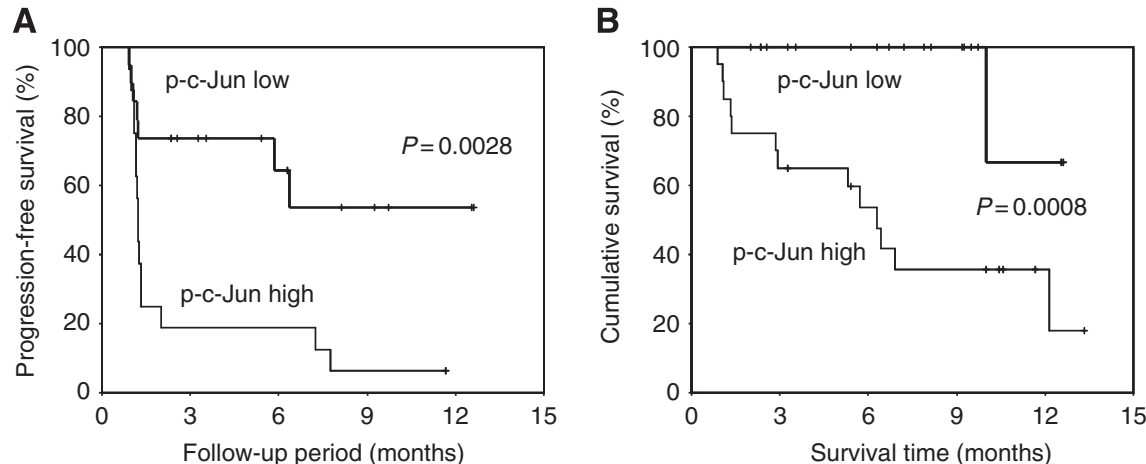

Figure 2 Association between JNK activation, decreased time to progression and OS in patients treated with sorafenib. The Kaplan-Meier method was used to determine progression-free survival $(\mathbf{A})$ and cumulative survival $(\mathbf{B})$. The log-rank test was used to compare progression-free survival and cumulative survival between patients grouped according to phospho-c-Jun expression levels.

A

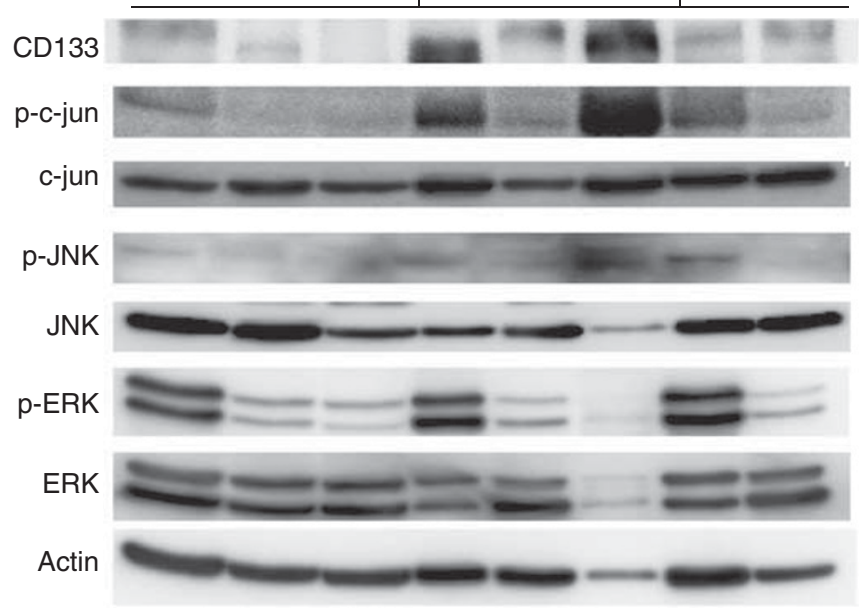

B
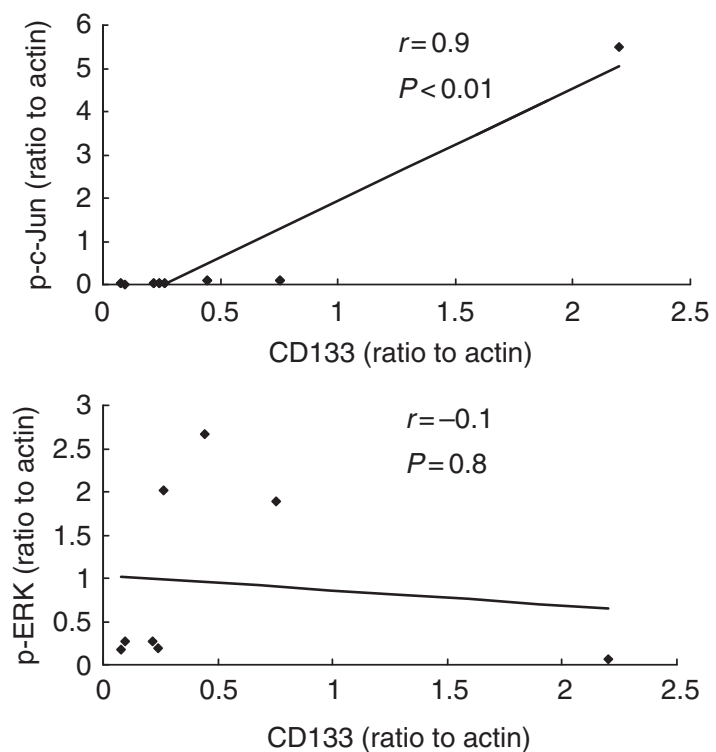

Figure 3 Relationship between CDI33, p-c-Jun, p-JNK and p-ERK expression levels in HCCs. (A) Lysates of human HCCs were gel separated and analysed by immunoblotting with antibodies to the indicated proteins. (B) There was a significant positive correlation between CDI33 and p-JNK/c-Jun expressions. There was no significant correlation between CDI33 and p-ERK expressions.
A
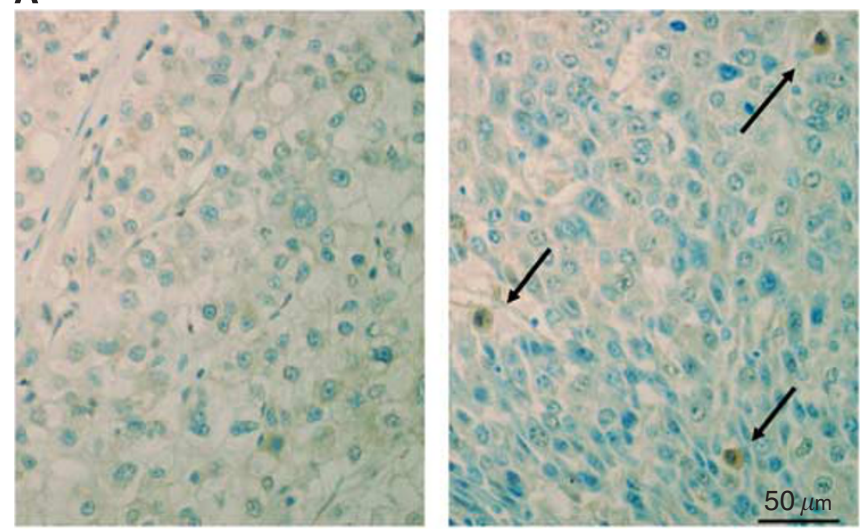

B

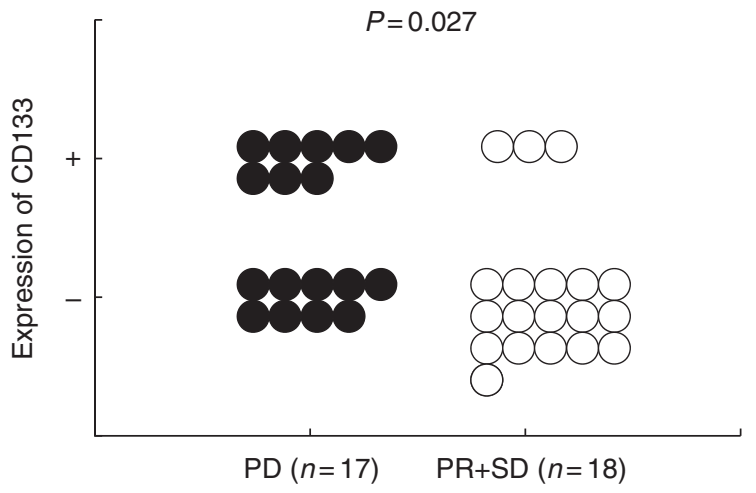

Figure 4 Correlation between CDI33 expression and response to sorafenib. (A) Expression of CDI33 in HCCs. Representative immunostaining of cases who exhibited PR (left) and PD (right). Paraffin-embedded liver sections were immunostained with anti-CD 133 antibody. (B) Among 17 non-responders (PD), 8 cases exhibited CDI33-positive cells. Among 18 responders (PR or SD), only three cases exhibited CD I33-positive cells.

\section{Association between JNK activation and CD133 expression in human HCCs}

In patients treated with sorafenib, expressions of CD133, phospho-c-Jun and phospho-ERK were examined. Hepatocellular carcinomas positive for CD133 was also positive for phospho-c-Jun and phospho-JNK (Figure 3A). There was a significant positive correlation between $\mathrm{CD} 133$ and phospho-c-Jun expressions $(r=0.854$ and $P=0.007)$. In contrast, there was no correlation 
between CD133 and phospho-ERK expressions $(r=0.254$ and $P=0.544$ ) (Figure 3B).

In patients treated with sorafenib, correlation between CD133 expression and efficiency of sorafenib treatment was examined. Among 17 objective non-responders (PD), 8 cases exhibited CD133-positive cells. In contrast, among 18 objective responders (PR or SD), only 3 cases exhibited CD133-positive cells. There was a significant correlation between $\mathrm{CD} 133$ expression and response to sorafenib $(P=0.027)$ (Figure $4 \mathrm{~B})$. According to the status of HCC at the initiation of sorafenib treatment, patients were classified as B (intermediate) or C (advanced) using Barcelona Clinic Liver Cancer (BCLC) staging system. There was no significant difference in JNK activity or CD133 positivity between BCLC stage B and stage C HCCs (data not shown).

We utilised FACS sorting to isolate CD133-positive and CD133negative cells from HepG2 cells. CD133 ${ }^{+}$cells and $\mathrm{CD} 133^{-}$cells were inoculated subcutaneously at $8 \times 10^{4}$ cells per body into nude mice. From 1 week after subcutaneous inoculation, TAT control peptide and D-JNKi were administered at $25 \mathrm{nmol}$ per mouse once a week and the mice were autopsied 4 weeks later. After autopsy, the volume of tumours was measured. $\mathrm{CD} 133^{+}$cells could efficiently initiate tumours in mude mice compared with $\mathrm{CD} 133^{-}$ cells (Figure 5A). CD133 ${ }^{+}$HepG2 cells produced large tumours in $100 \%$ of mice whereas $\mathrm{CD} 133^{-}$cell fractions produced only small

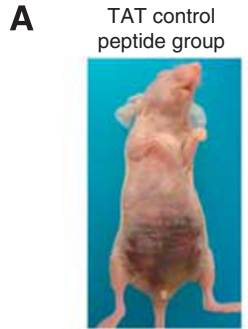

$\mathrm{CD} 133^{+/-}$

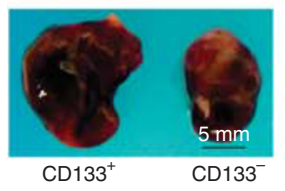

C

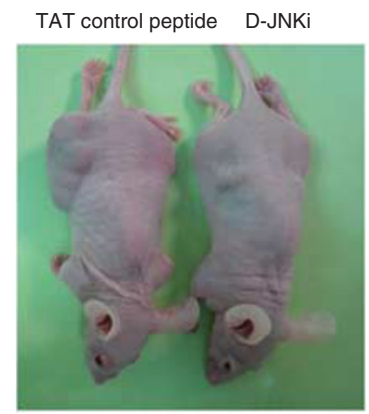

$\mathbf{E}$

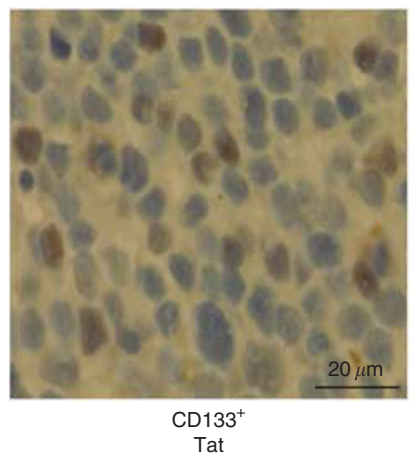

Planted HepG2; p-c-Jun

D-JNKi group

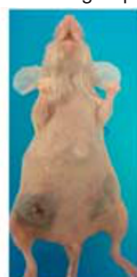

$\mathrm{CD}_{133^{+/-}}$

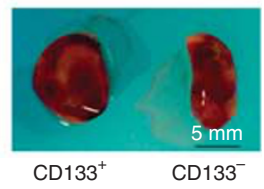

\section{D}

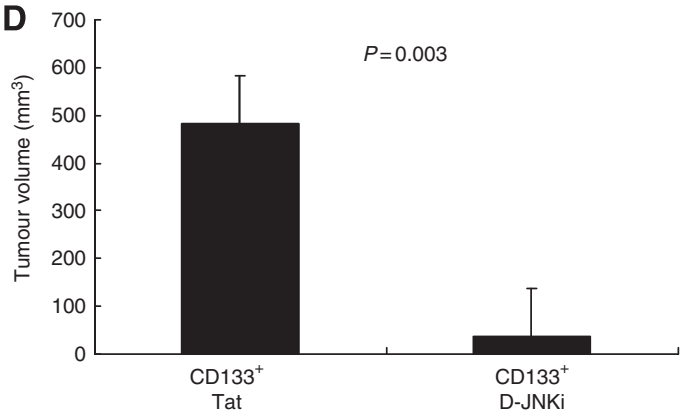

$\mathbf{F}$

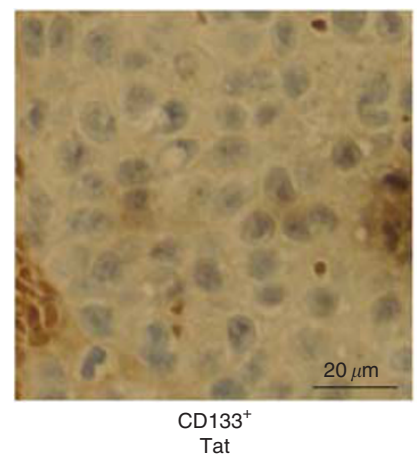

Figure 5 Effect of a JNK inhibitor on tumourigenic potential of CDI33 ${ }^{+}$HCC cells. (A) HepG2 cells positive or negative for CDI33 were inoculated subcutaneously at $8 \times 10^{4}$ cells per body into nude mice $(n=8)$. From I week after subcutaneous inoculation, TAT control peptide and D-JNKi, a specific JNK inhibitor, were administered at $25 \mathrm{nmol}$ per mouse once a week and the mice were autopsied 4 weeks later. Representative nude mice with subcutaneous tumours derived from $\mathrm{CDI} 33^{+}$(left) and $\mathrm{CDI} 33^{-}$(right) HepG2 cells. (B) Tumourigenicity of CDI33+ or CDI33- HepG2 cells treated with D-JNKi or control Tat protein. (C) HuH7 cells positive for CDI33 were inoculated subcutaneously at I $\times 10^{6}$ cells per body into nude mice $(n=6)$. From I week after subcutaneous inoculation. TAT control peptide and D-JNKi were administered at 25 nmol per mouse once a week and the mice were autopsied 4 weeks later. Representative nude mice with subcutaneous tumours were shown. (D) Tumourigenicity of $\mathrm{CDI} 33^{+} \mathrm{HuH7}$ cells treated with D-JNKi or control Tat protein. (E) Expression of phospho-c-Jun in xenografted tumours treated with D-jNKi or control protein. (F) Expression of phospho-JNK in xenografted tumours treated with D-JNKi or control protein. 


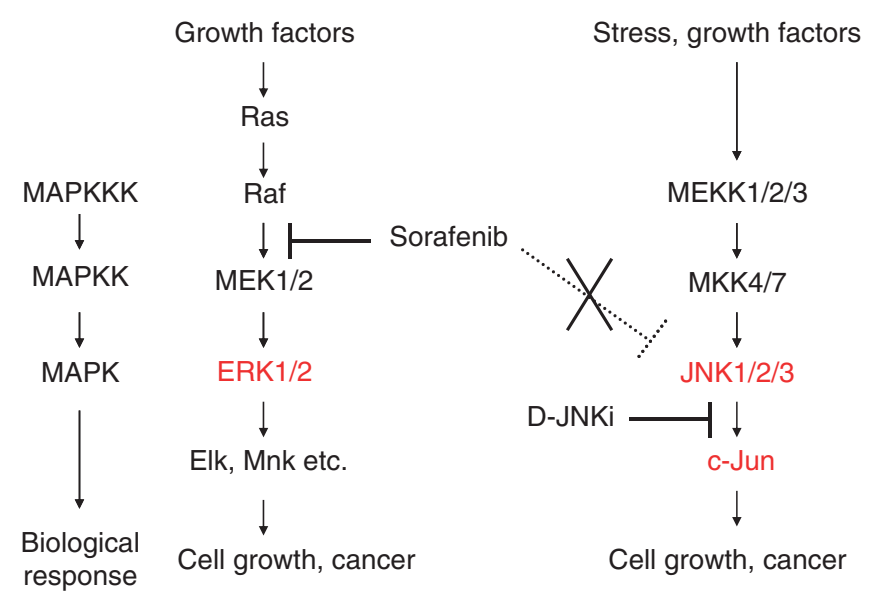

Figure 6 Association between sorafenib and the MAPK cascade. Sorafenib inhibits the Raf/ERK signalling pathway but not the JNK signalling pathway. The therapeutic efficacy of sorafenib would be limited when JNK is activated in HCCs. Treatment with sorafenib in combination with a JNK inhibitor might open promising therapeutic perspectives.

tumours in $50 \%$ of mice. On the other hand, mice treated with $\mathrm{D}$-JNKi showed a marked reduction in tumour-initiating capacity of $\mathrm{CD}_{133^{+}}$cells to the same level as in $\mathrm{CD} 133^{-}$cells (Figure 5B). Similar results were obtained using another HCC cell line, a HuH7 cell (Figure 5C and D). Indeed, D-JNKi suppressed the expression of p-c-Jun and p-JNK in HCC (Figure 5E and F) and p-c-Jun in HepG2 cells (Supplementary Figure 1).

\section{DISCUSSION}

The therapeutic options for advanced-stage HCC are limited because HCC responds poorly to systemic treatments such as conventional chemotherapy and radiotherapy. Cancer stem cells may be more resistant to chemotherapeutic agents than differentiated tumour cells possibly owing to an increased expression of adenosine triphosphate-binding cassette transporters and antiapoptotic proteins (Jordan et al, 2006). Thus, the development of an effective strategy to target cancer stem cell pools together with conventional chemotherapies is essential to eradicate a tumour mass (Dean et al, 2005). Recently, a $\mathrm{CD}_{133^{+}}$subpopulation of multipotent cells with extensive proliferative and self-renewal abilities was identified as cancer stem cells and was proven to contribute to the initiation and growth of HCC (Ma et al, 2007). Here, we showed that CD133 expression level is correlated with JNK activity and predicts response to sorafenib in human HCC. In addition, pharmacologic inhibition of JNK has reduced tumourinitiating capacity of $\mathrm{CD}_{133^{+}}$cells, suggesting that JNK activation in $\mathrm{CD} 133^{+}$HCC cells enhances their tumourigenic capacity. Given that increased JNK activity contributes to proliferative advantage (Sakurai et al, 2006; Hui et al, 2008), the majority of HCC cells differentiated from CD133 ${ }^{+}$HCC cells with increased JNK activity would inherit the phenotype and exhibit the enhanced JNK activation.

Surrogate biomarkers that predict the biological and clinical efficacy of sorafenib will help tailor treatment on an individual patient basis. The predictive value of Raf/MEK/ERK signalling activity for the efficacy of sorafenib in HCC remains uncertain (Abou-Alfa et al, 2006; Calvisi et al, 2006; Newell et al, 2009). To date, a robust predictive biomarker has not been developed. In this study, we found a strong correlation between elevated JNK activity and poor therapeutic response to sorafenib. Evaluation of JNK activity in HCC can be useful to differentiate between responders and non-responders before starting sorafenib treatment and help to select patients who are likely to benefit from the treatment. In addition to ERK-mediated HCC cell growth, sorafenib also targets tumour angiogenesis by inhibiting the receptor tyrosine kinases of VEGF receptor (VEGFR)-1, VEGFR-2, VEGFR-3 and plateletderived growth factor receptor $\alpha$ and $\beta$ and stem cell factor receptor (KIT) (Wilhelm et al, 2004, 2006). Thus, the extent of angiogenesis might be a biomarker that can predict clinical efficacy of sorafenib. However, there was no significant relationship between tumour angiogenesis as assessed by CD31 staining and the therapeutic response to sorafenib (data not shown). c-Jun $\mathrm{N}$-terminal kinase activity should be an independent predictive biomarker for sorafenib efficacy although this study is based on limited data of 39 patients from a single institution and further studies are needed to validate its value. Furthermore, we demonstrated that elevated JNK activity in HCC was associated with poor prognosis of patients treated with sorafenib. The ERK and JNK signalling pathways would activate mutually exclusive downstream molecules to contribute to HCC development. Consistently, JNK activation partially rescued sorafenib-induced cell toxicity, but was not sufficient to confer resistance to sorafenib (Supplementary Figure 2). These data suggest the possibility of using a JNK inhibitor as a second-line treatment of advanced HCC (Figure 6). In this study, we found that in human HCC, the activation of JNK and high expression level of CD133 are associated with resistance to sorafenib. CD133 expression level is linked to JNK activity whose inhibition significantly reduces tumourigenesis of human $\mathrm{CD}_{133^{+}}$HCC cells after xenotransplantation. Our results demonstrate the importance of JNK in human HCC, and the potential application of JNK targeting for HCC therapy.

\section{ACKNOWLEDGEMENTS}

We are grateful to $\mathrm{H}$ Kamata (Hiroshima University) and M Karin (UCSD) for providing the JNKK2-JNK1 expression construct and $\mathrm{AM}$ Park and $\mathrm{H}$ Munakata (Kinki University) for technical assistance and discussions. This research was supported by grants from Osaka Community Foundation and Grant-in-Aid for Scientific Research from the Ministry of Education, Science and Culture of Japan.

Supplementary Information accompanies the paper on British Journal of Cancer website (http://www.nature.com/bjc)

\section{REFERENCES}

Abou-Alfa GK, Schwartz L, Ricci S, Amadori D, Santoro A, Figer A, De Greve J, Douillard JY, Lathia C, Schwartz B, Taylor I, Moscovici M, Saltz LB (2006) Phase II study of sorafenib in patients with advanced hepatocellular carcinoma. J Clin Oncol 24: 4293-4300

Calvisi DF, Ladu S, Gorden A, Farina M, Conner EA, Lee JS, Factor VM, Thorgeirsson SS (2006) Ubiquitous activation of Ras and Jak/Stat pathways in human HCC. Gastroenterology 130: 1117-1128

Chang L, Karin M (2001) Mammalian MAP kinase signalling cascades. Nature 410: $37-40$

Dean M, Fojo T, Bates S (2005) Tumour stem cells and drug resistance. Nat Rev Cancer 5: 275-284

Dhillon AS, Hagan S, Rath O, Kolch W (2007) MAP kinase signalling pathways in cancer. Oncogene 26: 3279-3290

Eferl R, Ricci R, Kenner L, Zenz R, David JP, Rath M, Wagner EF (2003) Liver tumor development. c-Jun antagonizes the proapoptotic activity of p53. Cell 112: 181-192

Hagiwara S, Kudo M, Chung H, Ueshima K, Inoue T, Haji S, Watanabe T, Park AM, Munakata H, Sakurai T (2011) Activation of JNK in the 
non-cancerous tissue predicts a high risk of recurrence after hepatic resection. Hepatol Res 42: 394-400

Hui L, Bakiri L, Mairhorfer A, Schweifer N, Haslinger C, Kenner L, Komnenovic V, Scheuch H, Beug H, Wagner EF (2007) p38alpha suppresses normal and cancer cell proliferation by antagonizing the JNKc-Jun pathway. Nat Genet 39: 741-749

Hui L, Zatloukal K, Scheuch H, Stepniak E, Wagner EF (2008) Proliferati on of human HCC cells and chemically induced mouse liver cancers requires JNK1-dependent p21 downregulation. J Clin Invest 118: $3943-3953$

Jordan CT, Guzman ML, Noble M (2006) Cancer stem cells. N Engl J Med 355: $1253-1261$

Llovet JM, Ricci S, Mazzaferro V, Hilgard P, Gane E, Blanc JF, de Oliveira AC, Santoro A, Raoul JL, Forner A, Schwartz M, Porta C, Zeuzem S, Bolondi L, Greten TF, Galle PR, Seitz JF, Borbath I, Häussinger D, Giannaris T, Shan M, Moscovici M, Voliotis D, Bruix J, SHARP Investigators Study Group (2008) Sorafenib in advanced hepatocellular carcinoma. $N$ Engl J Med 359: 378-390

Ma S, Chan KW, Hu L, Lee TK, Wo JY, Ng IO, Zheng BJ, Guan XY (2007) Identification and characterization of tumorigenic liver cancer stem/ progenitor cells. Gastroenterology 132: 2542-2556

Newell P, Toffanin S, Villanueva A, Chiang DY, Minguez B, Cabellos L, Savic R, Hoshida Y, Lim KH, Melgar-Lesmes P, Yea S, Peix J, Deniz K, Fiel MI, Thung S, Alsinet C, Tovar V, Mazzaferro V, Bruix J, Roayaie S, Schwartz M, Friedman SL, Llovet JM (2009) Ras pathway activation in hepatocellular carcinoma and anti-tumoral effect of combined sorafenib and rapamycin in vivo. J Hepatol 51: 725-733

Sakurai T, He G, Matsuzawa A, Yu GY, Maeda S, Hardiman G, Karin M (2008) Hepatocyte necrosis induced by oxidative stress and IL-1 alpha release mediate carcinogen-induced compensatory proliferation and liver tumorigenesis. Cancer Cell 14: 156-165

Sakurai T, Kudo M (2011) Signaling pathways governing tumor angiogenesis. Oncology 81(Suppl): 24-29

Sakurai T, Maeda S, Chang L, Karin M (2006) Loss of hepatic NF-kappa B activity enhances chemical hepatocarcinogenesis through sustained c-Jun N-terminal kinase 1 activation. Proc Natl Acad Sci USA 103: 10544-10551

Schwabe RF, Bradham CA, Uehara T, Hatano E, Bennett BL, Schoonhoven R, Brenner DA (2003) c-Jun-N-terminal kinase drives cyclin D1 expression and proliferation during liver regeneration. Hepatology 37: 824-832

Tang KH, Ma S, Lee TK, Chan YP, Kwan PS, Tong CM, Ng IO, Man K, To KF, Lai PB, Lo CM, Guan XY, Chan KW (2011) CD133(+) liver tumor-initiating cells promote tumor angiogenesis, growth and selfrenewal through neurotensin/ IL-8/ CXCL1 signaling. Hepatology 55: $807-820$

Whittaker S, Marais R, Zhu AX (2010) The role of signaling pathways in the development and treatment of hepatocellular carcinoma. Oncogene 29: 4989-5005

Wilhelm S, Carter C, Lynch M, Lowinger T, Dumas J, Smith RA, Schwartz B, Simantov R, Kelley S (2006) Discovery and development of sorafenib: a multikinase inhibitor for treating cancer. Nat Rev Drug Discov 5: 835-844

Wilhelm SM, Carter C, Tang L, Wilkie D, McNabola A, Rong H, Chen C, Zhang X, Vincent P, McHugh M, Cao Y, Shujath J, Gawlak S, Eveleigh D, Rowley B, Liu L, Adnane L, Lynch M, Auclair D, Taylor I, Gedrich R, Voznesensky A, Riedl B, Post LE, Bollag G, Trail PA (2004) BAY 43-9006 exhibits broad spectrum oral antitumor activity and targets the RAF/ MEK/ERK pathway and receptor tyrosine kinases involved in tumour progression and angiogenesis. Cancer Res 64: 7099-7109

This work is published under the standard license to publish agreement. After 12 months the work will become freely available and the license terms will switch to a Creative Commons Attribution-NonCommercial-Share Alike 3.0 Unported License. 